\title{
ANALYSIS OF PRODUCER GAS CARBURETOR FOR DIFFERENT AIR- FUEL RATIOS USING CFD
}

\author{
Raj Reddy ${ }^{1}$, Pooja Reddy ${ }^{2}$ \\ ${ }^{1}$ Asst.Prof. Department of Mechanical engineering, BKIT Bhalki: 585328. Karnataka, India \\ ${ }^{2}$ Student, ECE Department, LAEC Bidar-585401, Karnataka, India
}

\begin{abstract}
From the different clean sources of fuel for power generation. Natural gas can utilize more because of availability in particular locations. in present condition of technological advances, the capable and maintainable renewable resources and new methods are making impact such as biomass, biomass based gasification system making a effective role in fulfilling the energy requirement. to analyze with all aspects for its mixing performance and response with a CFD Modeling producer gas was specially designed. Producer gas carburetor consists of a mixing chambers one for the air entry and another for the producer gas entry, for a engine having $25 \mathrm{kWe}$ ability, to generate stoichiometric mixture orifices are used at the inlets and using the induction of the engine efficiency. good mixing efficiency and we analyzed the flow analysis in details and suitable geometrical design description using CFD simulation.
\end{abstract}

Keywords-Carburetor, Computational fluid dynamics, Producer Gas, Air/Fuel ratio, Turbulence ****

\section{INTRODUCTION}

The natural choice is a non-conventional energy source. One of the non-conventional energy resources is a biomass. Using the plants, leaving on the earth and related to water their products can be used to produce the biomass. Energy from biomass can be acquired through the conversion technologies such as: Direct combustion, biochemical conversion and thermo chemical conversion. Thermo chemical conversion takes two forms: Gasification and liquefaction. The biomass can obtained from the different methods like rice husk, bagasse etc, using the biomass we can develop the resultant gas known as producer gas. The producer gas alone can be used in SI engine and can be used as dual fuel mode in the CI engine. Energy obtaining from the biomass gasification is the only method for the economical and eco friendly to the nature. In present situation. Cleaner fuels for the power generation through the ic engine methods are the gaseous fuels. The reciprocating and turbine machinery are the power generation packages. Using the gaseous fuels we can obtain complete combustion and very less effect of emission on the environment. Because of these features presently gaseous fuels are more demanding and requirement in the present world for power generation., We getting many services from the ic engine from many years but other hand that is effecting more to the environment by the harmful pollutants. certainly in several countries with insufficient environmental consciousness. Therefore, large impetus is being given to improve the efficiency and thereby by improving the different design changes of an a engine and use of alternate fuels in place of fossil fuels we can reduce the emission effect on the environment. Because of more cleaner combustion gaseous fues receive more concentration among the alternate fuels.
In the domain of alternate fuels, oxygenated liquid and gaseous fuels receive more prominence because of the possibilities of cleaner combustion. produce gas is an echo friendly fuel because of its property, producer gas obtained from the biomass holds a very less effect on the environment. To This producer gas when added to carbon dioxide neutral generates lesser quantum effect on the environment. Because of these Many merits biomass has got attention towards this widely but still technological modification not done upto the mark. In the present situation emission affects a lot to the environment, so we need to reduce emission effect on the environment as much as possible.. Producer gas can be obtained from the gasification process which we can used in direct injection engine because the producer gas obtained from the gasification process is a combustible fuel that is clean. So to use these fuels in the biomass power plants, we have to make changes in the components and as well as in the design changes in the components according to the our requirement. Since the energy crisis through the biomass is very essention for present situation. So what the components need and what the modification need in the components design, so everything we should analyze in details. Among this we chosen one of the important component that is carburetor, so what the changes we have to do regarding carburetor to get a good proper mixing of fuel and other applications.

It is also a momentum on us by generating a gas from the municipal wastes and industrial wastes, called them as land fill gas, diluted natural gas and biogas. By the process of thermo chemical conversion can use for any solid organic matter. The gas obtained from these methods are echo friendly and as well economical. 
To use producer gas we have to develop a special types of engine which will suit to a producer gas and the required design parameters we have to change. The exhaust emission is mainly effected due to the effect of Air/fuel ratio characteristic in that due to the properties of fuels and because of improper mixing of air and fuel. Present days there is demand for minimum emission with high efficiency fuel is required. To develop a better engine performance all conditions has to be satisfied as we discussed above. Generally carburetors defined as a device used to mix the air fuel properly before sending to the combustion chamber. An perfect carburetor would give a mixture of suitable air fuel ratio range to the engine more than a whole range of operation. To guarantee proper performance, carburetor should have unmistakable clear adjustment procedures and as well as it should be reproducible. For the flow analysis CFD version Gambient and Fluent are used for $\mathrm{k}$ epsilon RNG turbulence model is used . using ANSYS workbench geometric model was developed.

\subsection{Producer Gas Fuel:}

Producer gas fuel: From the unfinished burning of Biomass, Normally contains $2 \%$ of methane, $18-0 \%$ of hydrogen and carbon monoxide and rest motionless like carbon di-oxide and nitrogen. It is having lower calorific value range from 4.44.9MJ/KG, with air to fuel ration being $1.25+0.05$ on the basis of mass. When compare the producer gas with the pure gas like methane, it is more efficient with regard to the ic engine process, since engine operating on these fuels are moreover close to pure methane or diluted methane. The correspondence ratio of air fuel mixture at the inflammability restrict compares for the both the gases, at the lean limits burning velocity for the producer gas is much higher. $0.5 \mathrm{~m} / \mathrm{sec}$ is the burning velocity for producer gas. Due this characteristic demand is to decrease the advancement in the timing of ignition.

Similar to other gaseous fuel, it is clean enough such that the passage present in the intermediary, fuel want to occupy but it as clean so the contaminate does not occupy that vacant space present in the cylinder of internal combustion engine. Because some of the disadvantages like auto-ignition at high compression, due to the low energy density, large de-rating in power because these characteristics, producer gas largely have been unexploited. However these characteristics are needed to be re-examined and detail analysis. Much more clarification required with regards to the knocking tendency, Due the high burning velocity because of presence of hydrogen might suppress the pre-flame reactions that are the reason for the knocking on account of increased dilution. Compare to the conventional fuels like methane, producer gas having a maximum flame temperature attainable characteristic, so one can expect the better knock resistivity.

\subsection{Producer Gas Carburetor:}

Producer gas carburetor: the device used for the mixing of air and fuel for the engines generally termed as a carburetors, which is generally refered for the spark ignition engines, this is used as the intake manifold in the combustion engine. For any ic engine at a particular load range and the speed range requires a proper mixing of air and gaseous fuel at a proper ratio in the carburetor. Effortlessness and severity have always been considered as common requirement to achieve problem free modification and reproducible performance, while designing the carburetors we have to consider these parameters. By taking a appropriate coefficient of discharge the effective area reduction of gas and air entry holes has to be consider. The fuel will enter in the mixing chamber of the carburetor via orifices which have baffle plates that enables proper mixing of air and fuel. The design of producer gas carburetors are made such a that air and fuel flow at ambient conditions to be stoichiometry The fuel in this case would be Producer Gas generated from biomass gasification systems after having been modified for some of its components..

The blend of air and producer gas can then be fed into Direct Injection Engines for combustion purposes

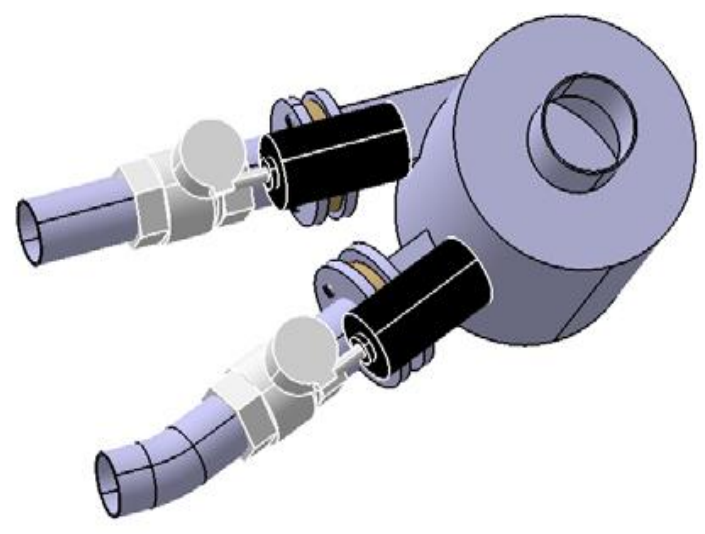

Fig 1: Experimental setup of PG Carburetor

A engine with a suction pressure of $25 \mathrm{kWe}$ which is having the orifices placed at the entry of the air and gaseous fuel such that these should be stoichiometry at the ambient flow condition as shown in the figure 1 . The butterfly valve which located prior to the air and fuel inlet orifices are used to manage the flow of quantity fuel inside the carburetor. To obtain stoichiometry of air and fuel, the pressure balancing electronic controller drives suitable the butterfly with help of a motor are used that brings the valves for a null pressure differential crossways the manifolds for the fuel and air attached upstream to the main engine manifold and works in suction pressures. To match the ideal mixture condition manifolds are turned for the effective flow areas. Due to this we get a stoichiometry at the ambient condition. For a good mixing ability for optimal pressure drop, producer gas carburetors are designed and comprehensively analyzed. Orifices are used maintain the airfuel ration mixture at a stoichiometry and these designed based on the mass flow rate of fuel required for the ic engine. 


\section{LITERATURE}

In the present situation emission affects a lot to the environment, so we need to reduce emission effect on the environment as much as possible. . Klimstra $\mathbf{J}$ et al. [1 Investigated that Present technological improvement situation, it is found that viable and sustainable renewable resources like biomass and new methods rising out of these systems come across a major responsibility in bridging the energy disaster.

N.K.S.Rajan et al. [2] developed the To use producer gas fuel in the direct injection gas engines, advanced biomass gasification system are used to generate producer gas. However in order to use standard gas engines few of its components need to be modify before they are used in the biomass power plants. This is the emerging are around the world but still technology not spread around the world. So before they used it is necessary that whatever the design modification we are doing that should be analyzed in detail and we have to give the clear picture to use those components why we are using and why we are doing the changes. Among those components carburetor is also a one of important component and is found that supplementary study we have to be carried out in developing a design procedure for this application.

Yoshishige Ohyama et al. [3] Studied how the With increasing demand of emission less fuel, to get this we have to supply proper air fuel ratio to the IC engine combustion chamber which is fine defined mixture under all condition has become additional necessary for improved engine performance. The device used where a flow induced pressure drop forces a fuel flow into the air stream is called carburetor. Engine over its complete range of operation from no load to full load condition, ideal carburetor should provide a air fuel mixture at appropriate rate. Further T.R.Anil et al. [4] Investigated the Analysis of a Mixture Flow in a Producer Gas Carburetor using a CFD with a CFX. Versteeg, H.K. et al. [5] Carried out study on introduction to CFD-The finite volume method. at present, for power production gaseous fuels like producer gas ahead importance as cleaner fuels through IC engine. Gaseous fuels main feature is complete combustion of a fuel with minimum emission and this property at this time being exploited the world-over for power production purpose. Among the dirt free sources of fuel for power generation, natural gas has been exploited largely amongst the clean sources of fuel for power production due to vital availability in definite position. Similarly, there is also an momentum on using gas generated from industrial and municipal wastes, specifically diluted natural gas - biogas and land-fill gas.

\section{GEOMETRIC MODELING}

The below fig.2 shows designing of the producer gas carburetor, minimalism and gentleness have for all time been considered as a essential condition to accomplish easy alteration and reproducible performance. The effective area reduction of gas and air entry holes is considered by taking a suitable coefficient of discharge. The air and fuel flow is through orifices into the mixing chamber of the carburetor which enables proper mixing of air and fuel. The producer gas carburetor is being designed to have air and fuel flow at ambient conditions to be stoichiometry.

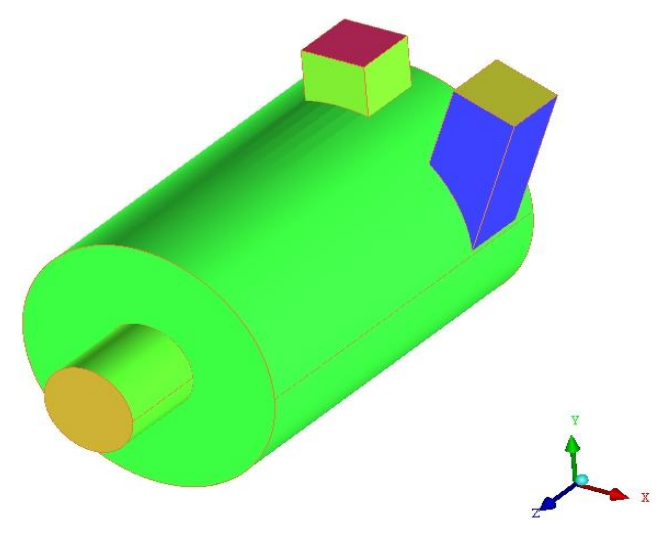

Fig 2: Simplified model of PG Carburettor

To get stoichiometry at a ambient flow condition orifices are placed at the entry of the orifices in the producer gar carburetor of a engine having capacity of $25 \mathrm{kWe}$. Butterfly valves are used control the percentage of fuel entering into the carburetor and to vary the flow of fuel mixture. To maintain the stoichiometric condition pressure balancing electronic controller are used to drive suitably the butterfly valve with the help of a motor to null pressure differential across the manifolds of an a producer gas carburetor.

The air and producer gas passes through inlets of $50 \mathrm{~mm}$ x $50 \mathrm{~mm}$. The air inlet is kept tangential to the mixing chamber whereas producer gas inlet is radial to the mixing chamber. The outlet diameter is $35 \mathrm{~mm}$ based on the inputs for Reynolds number and velocity at the outlet assuming air at Standard Temperature Pressure. Air and producer gas enter into mixing chamber through an orifice of $28.0 \mathrm{~mm}$ and $26.5 \mathrm{~mm}$ diameter respectively. This will not be considered in the CFD analysis.

\subsection{Grid Generation:}

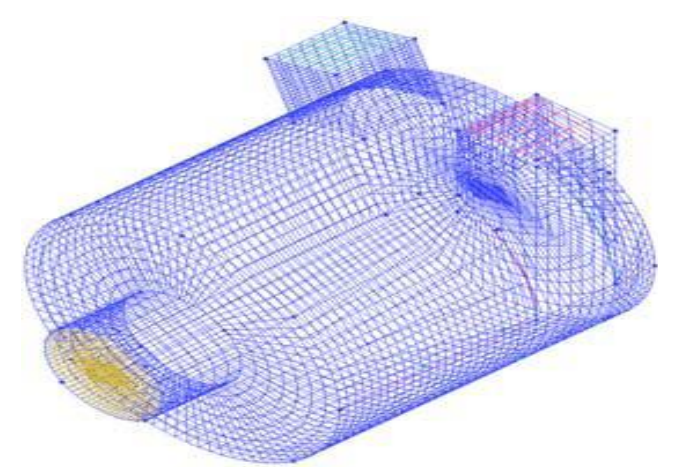

Fig 3: Mesh Model of Geometry 
Analysis will be done to determine the flow field, air/producer gas distribution for geometrical configurations at different air and fuel flow rates as reported in the experimental set-up. ANSYS ICEM CFD will be used for generating multi-block structured mesh for the geometries and ANSYS FLUENT will be used for doing the single phase multi species flow simulation.

\subsection{Domain Conditions:}

The CFD simulation will not include the orifices preceding the inlets but the geometry as described in Figure1. A single phase, multispecies simulation will be carried out under atmospheric isothermal operating conditions for the geometry for the different set of air and PG boundary conditions. Turbulence will be modeled according to the k-e RNG turbulence model with wall functions for near wall treatment. A total of 7 transport equations will be solved: 1 continuity, 3 momentum, 2 turbulence and 1 species equation for producer gas. The mass fraction of air being abundant will be calculated from the constraint relationship of (mass fractions of species) $=1$.

\section{MATERIAL PROPERTIES:}

Air ideal gas and Producer gas are considered to be different species with their averaged properties based on their individual constitution. The following volume percentage has been considered based on the experimental data available in the literature.

Table 1: Material Properties

\begin{tabular}{|l|l|l|}
\hline Component & $\begin{array}{l}\text { Air } \\
(\%)\end{array}$ & $\begin{array}{l}\text { Producer } \\
\text { Gas (\%) }\end{array}$ \\
\hline Carbon dioxide & 0.03 & 12.5 \\
\hline Carbon Monoxide & 0.01 & 21 \\
\hline Hydrogen & 0 & 21 \\
\hline Argon & 0.86 & 0 \\
\hline Methane & 0 & 3.5 \\
\hline Oxygen & 21 & 0 \\
\hline Nitrogen & 78 & 42 \\
\hline Total & 100 & 100 \\
\hline
\end{tabular}

Table 2: The Transport and Specific properties of Air and producer gas

\begin{tabular}{|l|l|l|}
\hline Property & Air & PG \\
\hline Density (Kg/m3) & 1.175 & 0.978 \\
\hline Viscosity (Pa.S) & $1.179 \times 10-5$ & $1.452 \times 10-5$ \\
\hline Specific Heat (J/kg-k) & 1005.148 & 3838.358 \\
\hline $\begin{array}{l}\text { Thermal conductivity } \\
\text { (W/m-K) }\end{array}$ & 0.0240 & 0.0535 \\
\hline
\end{tabular}

\section{BOUNDARY CONDITIONS}

The problem set-up has static pressure at the inlets and mass flow at outlets. As ANSYS FLUENT will be used in the present analysis, we will be using the experimental mass flow rates at the air and PG inlets and pressure outlet at the outlet boundary. Being subsonic for air inlet boundary condition mass and momentum, static pressure equivalent to domain reference pressure is set with flow condition. Flow through the air inlet with air ideal mass fraction as 1 is considered. The initial boundary condition for fuel inlet is same as the air inlet except for the flow of producer gas mass fraction being 1 at the inlet. The boundary condition for carburetor outlet is of different mass flow rate which is to be simulated is considered.

\section{METHODOLOGY}

To simulate the turbulence parameters, a standard k- $\varepsilon$ model has been chosen with isothermal heat transfer condition at 300 $\mathrm{K}$. we consider k- $\varepsilon$ model with two new variables.

For the different $\mathrm{A} / \mathrm{F}$ ratio and for the geometrical configurations, the massfraction distribution will be reported as mf_spread, defined as,

$$
m f \text { spread }=\frac{2 \sqrt{\text { Ypgi }-\mathrm{Ypg}(\mathrm{avg})}}{n}
$$

Where, Ypg,i = mass fraction of 'pg' at the $i$ th face on the outlet surface

Ypg avg = average mass fraction of PG on the outlet surface $\mathrm{n}=$ Number of faces on the outlet surface

The flow field will be described by plotting the following on 3 different planes for the geometric configurations at one design point only.

a. Velocity and pressure contours

b. Mass fraction plots for producer gas

\section{RESULTS AND DISCUSSION}

Air fuel Ratio: (PG: 9.423, AIR: 27.62)

Mass Fraction: It is observed that Mass fraction is high at air inlet and low at PG inlet and in medium range around 0.0005 at outlet. This is to be considered as a good enough for premixed combustion.

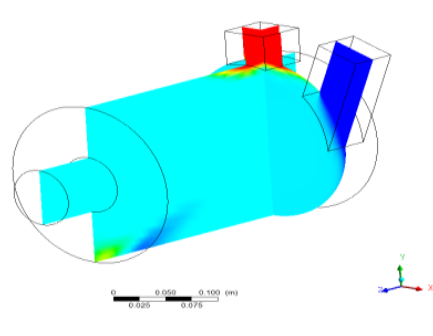

Fig 4: Mass Fraction 
Pressure contour: It is observed that pressure is around 40000Pa at inlet and very low at outlet around 5000Pa

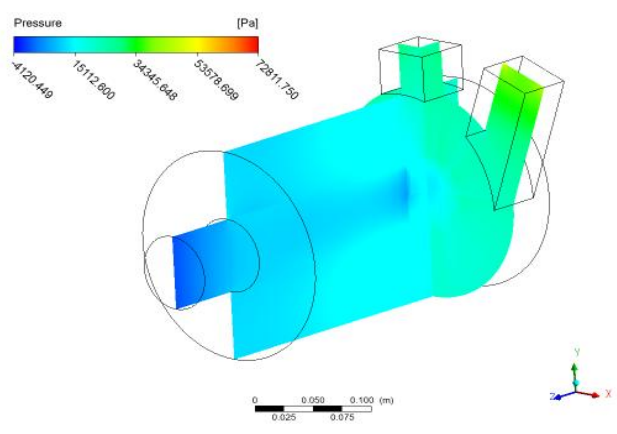

Fig 5: Pressure Contour

Velocity Contour: It is observed that velocity is very low at inlet and outlet and high in the middle section of the cylinder around $100 \mathrm{~m} / \mathrm{sec}$.

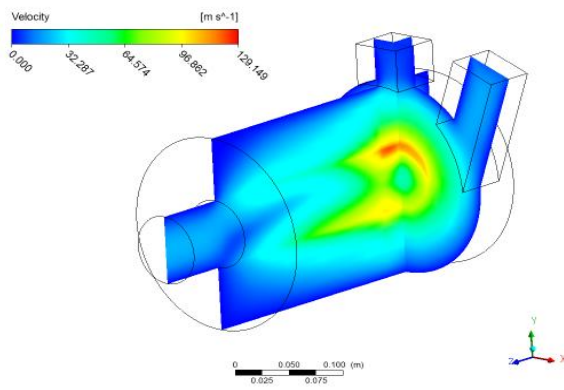

Fig 6: Velocity Contour

Similarly we obtain the results for different airfuel air-fuel ratios as show in below

Table 3: mass fraction for different airfuel ratios

\begin{tabular}{|l|l|l|l|l|l|}
\hline Sl. & $\begin{array}{l}\text { PG- } \\
\text { Rate } \\
\text { g/s }\end{array}$ & $\begin{array}{l}\text { Air } \\
\text { Rate } \\
\text { g/s }\end{array}$ & $\begin{array}{l}\text { Air- } \\
\text { PG } \\
\text { ratio }\end{array}$ & Mf Spread & $\begin{array}{l}\text { Pressure } \\
\text { Drop } \\
\text { Pa }\end{array}$ \\
\hline 1 & 9.423 & 27.62 & 2.931 & 0.0005763 & 36919.55 \\
\hline 2 & 13.32 & 27.62 & 2.074 & 0.0008181 & 29884.05 \\
\hline 3 & 16.32 & 27.62 & 1.692 & 0.0008883 & 31426.9 \\
\hline 4 & 18.85 & 27.62 & 1.465 & 0.0009427 & 32731.95 \\
\hline 5 & 21.07 & 27.62 & 1.311 & 0.0009892 & 33880.45 \\
\hline 6 & 23.08 & 27.62 & 1.196 & 0.0010314 & 34918.8 \\
\hline 7 & 24.93 & 27.62 & 1.108 & 0.00106837 & 35875.85 \\
\hline
\end{tabular}

\section{CONCLUSIONS}

The effect of air fuel ratio on Producer Gas Carburetor analysed by considering the turbulent model based on k- $\varepsilon$ theory with a RANS code has been used for the CFD predictions of the producer gas mass fraction, pressure drop and the carburetor performance has been evaluated leading to bringing out of an optimal design of the PG carburetor that is used for prototype testing and real-time testing. It is observed that mass fraction obtained is considered to be good for premixed combustion, so there will be a proper mixing of air and fuel. Since there will be a proper mixing the emission produced will be low. air-fuel ratio variations and the movement of both air and producer gas is towards maintaining the stoichiometric air-fuel ratio is analysed. The validation of the statement is justified with the available air-fuel data.

\section{REFERENCES}

[1]. Klimstra J "Carburetors for Gaseous Fuels -on Air to Fuel ratio, Homogeneity and Flow restriction. SAE paper 892141.

[2]. Versteeg, H.K. and Malalasekara, w. An introduction to CFD-The finite volume method, 1995 (Longman Scientific and Technical).

[3]. T.R.Anil, P.G.Tewari N.K.S.Rajan An Approach for Designing of Producer Gas Carburetor for Application in Biomass based Power Generation Plants proceedings of the national conference of Natcon 2004 Bangalore.

[4]. Yoshishige Ohyama, "Air /fuel ratio control using upstream models in the intake system." SAE paper 0857 vol1 1999.

[5]. T.R.Anil, S.D.Ravi, M.Shashikanth, N.K.S.Rajan P.G.Tewari. "CFD Analysis of a Mixture Flow in a Producer Gas Carburettor" International Conference On Computational Fluid Dynamics, Acoustics, Heat Transfer and Electromagnetics CFEMATCON-06, July24-25, 2006, Andhra University, Visakhapatnam-530003, INDIA 